\title{
Rosiglitazone ameliorates insulin resistance in brown adipocytes of Wistar rats by impairing TNF- $\alpha$ induction of p38 and p42/p44 mitogen-activated protein kinases
}

\author{
R. Hernandez ${ }^{1}$ T. Teruel ${ }^{1}$ C. de Alvaro ${ }^{1}$ M. Lorenzo $^{1}$ \\ ${ }^{1}$ Department of Biochemistry and Molecular Biology II, Faculty of Pharmacy, Complutense University, Madrid, Spain
}

\begin{abstract}
Aims/hypothesis. TNF- $\alpha$ caused insulin resistance on glucose uptake and on insulin signalling in fetal brown adipocytes. Since treatment with TNF- $\alpha$ activates stress kinases, including c-jun $\mathrm{NH} 2$ terminal kinase (JNK), and p42/p44 and p38 mitogen-activated protein kinases (MAPK), we explored the contribution of these pathways to insulin resistance by TNF- $\alpha$. Rosiglitazone is used to treat Type 2 diabetes as it improves insulin sensitivity in vivo. However, its ability to ameliorate $\mathrm{TNF}-\alpha$-induced insulin resistance in brown adipocytes remains to be explored.

Methods. We used fetal rat primary brown adipocytes cultured with TNF- $\alpha$, with or without stress kinase inhibitors or rosiglitazone, and further stimulated with insulin. Then, we measured glucose uptake and GLUT4 translocation. To determine the insulin signalling cascade, we submitted cells to lysis, immunoprecipitation and immunoblotting.
\end{abstract}

Received: 27 February 2004 / Accepted: 22 April 2004

Published online: 9 September 2004

(C) Springer-Verlag 2004

M. Lorenzo ( $)$

Department of Biochemistry and Molecular Biology II,

Faculty of Pharmacy, Complutense University,

28040-Madrid, Spain

E-mail: mlorenzo@farm.ucm.es

Tel.: +34-91-3941858, Fax: +34-91-3941779

Abbreviations: ECL, enhanced chemiluminiscence · ERK, extracellular signal-regulated kinase · IKK, inhibitor kB kinase · JNK, c-jun NH2 terminal kinase $\cdot$ MAPK, mitogen-activated protein kinase $\cdot$ MBP, myelin basic protein - MEM, minimal essential medium $\cdot$ PI, phosphatidylinositol $\cdot$ PKC, protein kinase C $\cdot$ PMSF, phenylmethylsulfonyl fluoride $\cdot$ PPAR, peroxisome proliferator-activated receptor - TLC, thin layer chromatography
Results. Exposure to TNF- $\alpha$ for $24 \mathrm{~h}$ impairs insulin stimulation of the phosphatidylinositol (PI) 3-kinase activity associated with IRS-2 and Akt activity. Pretreatment with PD98059 or PD169316, which inhibit p42/p44MAPK and p38MAPK respectively, restored insulin signalling and insulin-induced glucose uptake in the presence of TNF- $\alpha$. However, in the presence of SP600125, an inhibitor of JNK, TNF- $\alpha$ still produced insulin resistance. Rosiglitazone ameliorated insulin resistance by TNF- $\alpha$ in brown adipocytes, restoring completely insulin-stimulated glucose uptake and insulin-induced GLUT4 translocation to plasma membrane in parallel to the insulin signalling cascade IRS-2/PI 3-kinase/Akt.

Conclusions/interpretation. Rosiglitazone treatment impaired TNF- $\alpha$ activation of $\mathrm{p} 38$ and p42/p44MAPK, restoring insulin signalling and leading to normalisation of glucose uptake.

Keywords Akt - Glucose uptake - GLUT4 translocation · Insulin $\cdot$ JNK $\cdot$ p38MAPK · p42/p44MAPK · PI 3-kinase $\cdot$ Rosiglitazone $\cdot$ TNF- $\alpha$

\section{Introduction}

Insulin resistance is an important contributor to the pathogenesis of Type 2 diabetes mellitus. Tumour necrosis factor- $\alpha$ has been proposed as a link between adiposity and the development of insulin resistance, since most Type 2 diabetic patients are obese and have increased TNF- $\alpha$ expression in fat cells, and obese mice lacking TNF- $\alpha$ function are protected from developing insulin resistance $[1,2,3]$. Direct exposure of isolated cells to TNF- $\alpha$ inhibits insulin signalling and induces a state of insulin resistance in several systems including 3T3-L1 cells and human primary adipocytes $[4,5,6]$. The mechanism by which this 
happens involves Ser phosphorylation of IRS-1, which converts IRS-1 into an inhibitor of the insulin receptor Tyr kinase activity [7, 8]. Moreover, Ser307 has been identified as a site for TNF- $\alpha$ phosphorylation of IRS-1, with activation of c-Jun N-terminal kinase (JNK) being involved in the phosphorylation of this residue $[9,10]$. In this regard, ablation of $J n k 1$ decreases the development of insulin resistance associated with dietary obesity [11]. Other studies suggested that $\mathrm{p} 42 / \mathrm{p} 44$ and $\mathrm{p} 38$ mitogen-activated protein kinases (MAPKs) inhibit insulin signalling by diverse mechanisms in 3T3-L1 adipocytes [12, 13]. Recent work also implicated activation of inhibitor $\mathrm{kB}$ kinases (IKK) by TNF- $\alpha$ on Ser phosphorylation of IRS-1 [14], while IKK inhibition with salicylate or targeted disruption of $I k k \beta$ reversed obesity- and diet-induced insulin resistance [15].

Brown adipose tissue is a target tissue for insulin action, especially during late fetal development, when insulin supports survival, promotes adipogenic and thermogenic differentiation and regulates glucose uptake $[16,17,18]$. Acute insulin treatment stimulates glucose transport in brown adipocytes largely by mediating translocation of GLUT4 from an intracellular compartment to the plasma membrane, involving the activation of phosphatidylinositol (PI) 3-kinase, Akt 1 and 2 isoforms and the atypical protein kinase $\mathrm{C}$ (PKC) isoform $\zeta[19,20,21]$. We have previously described that TNF- $\alpha$ caused insulin resistance in brown adipocytes by decreasing IRS-2 Tyr phosphorylation and IRS-2-associated PI 3-kinase activity, while IRS-1 signalling was unaffected [22]. Furthermore, we had identified ceramide production as one of the mediators of insulin resistance by TNF- $\alpha$ and found that exogenously added C2-ceramide inhibited Akt activity through a ceramide-activated phosphatase [23]. However, other mediators activated in response to TNF- $\alpha$, such as stress kinases and inflammatory pathways, could also contribute to insulin resistance in brown adipocytes.

An insulin-sensitising drug from the thiazolidinediones family, rosiglitazone improves insulin action in vivo and in vitro across a wide spectrum of insulinresistant states, and has recently been introduced in the treatment of Type 2 diabetes [24, 25, 26]. Brown adipocytes are also a target for rosiglitazone action since they show high expression of peroxisome proliferator-activated receptor (PPAR) $\gamma$, and rosiglitazone increased expression of the thermogenic uncoupling protein by binding to the PPAR $\gamma$ response element described in the enhancer of this gene [27]. We have also shown that rosiglitazone produces insulin sensitisation in cultured brown adipocytes [28]. Therefore, this cell model is an ideal system for investigating the effectiveness of rosiglitazone in the treatment of insulin resistance induced by TNF- $\alpha$.

\section{Materials and methods}

Materials. Insulin, BSA (fraction V, essentially fatty-acid-free) and myelin basic protein (MBP) were from Sigma (St. Louis, Mo., USA). TNF- $\alpha$ was purchased from Pharma Biotechnologie (Hanover, Germany). Rosiglitazone was kindly provided by $\operatorname{Dr}$ S. A. Smith (Glaxo SmithKline, Harlow, UK). PD169316 and PD98059 were purchased from Calbiochem (Calbiochem-Novabiochem Intl, La Jolla, Calif., USA). SP600125 was from Alexis (Lausen, Switzerland). Fetal calf serum, PBS and culture media were from Invitrogen (Paisley, UK). Autoradiographic films were Kodak X-O-MAT/AR (Eastman Kodak, Rochester, N.Y., USA). We purchased 2deoxy-D $\left[1-{ }^{3} \mathrm{H}\right]$-glucose $(444 \mathrm{GBq} / \mathrm{mmol}),\left(\gamma^{32} \mathrm{P}\right)$ ATP and protein G-sepharose from Amersham Bioscience (Little Chalfont, UK). The anti-GLUT1 and anti-GLUT4 antibodies were supplied by Chemicon (Tamacula, Calif., USA). The anti-phospho and anti- (Akt, p42/p44MAPK, p38MAPK, JNK) antibodies were from Cell Signalling (Beverly, Mass., USA). We obtained antibodies against IRS-1 and IRS-2 from Upstate Biotechnology (Lake Placid, N.Y., USA), against caveolin-1(N-20) "sc894" from Santa Cruz (Palo Alto, Calif., USA) and the mouse anti-FAS antibody from BD Biosciences Pharmingen (San Diego, Calif., USA). All other reagents used were of the purest grade available.

Cell culture. Fetal brown adipocytes were obtained from interscapular brown adipose tissue of 20-day Wistar rat fetuses and isolated by collagenase dispersion [29]. Isolated cells were plated in tissue culture dishes $\left(1 \times 10^{6}\right.$ cells per 60 -mm diameter dish or at $4 \times 10^{6}$ cells per $100-\mathrm{mm}$ diameter dish) in minimal essential medium (MEM) with Earle's salts supplemented with $10 \%$ FCS, the presence of serum being essential for the cells to attach to the plastic surface of the dishes. After 4 to $6 \mathrm{~h}$ of culture at $37{ }^{\circ} \mathrm{C}$, cells were rinsed twice with PBS and a $70 \%$ confluent monolayer was observed under inverse light microscopy. Cells were maintained for $20 \mathrm{~h}$ in a serum-free MEM medium supplemented with $0.2 \%$ (w/v) BSA and then cultured for $24 \mathrm{~h}$ in the absence or presence of $1 \mathrm{nmol} / \mathrm{TNF}-\alpha$ without or with the following inhibitors: $800 \mathrm{nmol} / \mathrm{l}$ PD169316,

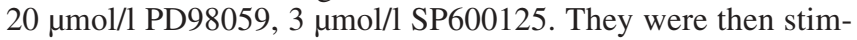
ulated or not for 5 or 30 minutes with $10 \mathrm{nmol} / \mathrm{l}$ insulin. In another group of experiments cells were cultured for $24 \mathrm{~h}$ in the presence of TNF- $\alpha$ without or with $10 \mu \mathrm{mol} / 1$ rosiglitazone, prior to insulin stimulation.

Wistar rats were obtained from the Complutense University Animal House. The principles of laboratory animal care were followed and the study was approved by the local ethics committee and carried out in accordance with the Declaration of Helsinki.

Glucose transport determination. Glucose transport was measured by incorporating 2-deoxy-D $[1-3 \mathrm{H}]$-glucose into cells during the last 10 min of culture as described previously [19]. Results are expressed as $\mathrm{dpm} / \mu \mathrm{g}$ of protein or as fold increase over basal.

Subcellular fractionation. Cells were washed with ice-cold PBS and scraped into the homogenisation buffer containing: $20 \mathrm{mmol} / \mathrm{l}$ Tris-HCl, $2 \mathrm{mmol} / \mathrm{l}$ EGTA, $2 \mathrm{mmol} / \mathrm{l}$ EDTA, $1 \mathrm{mmol} / \mathrm{l}$ phenylmethylsulfonyl fluoride (PMSF), $10 \mathrm{mmol} / \mathrm{l}$ $\beta$-mercaptoethanol, $10 \mu \mathrm{g} / \mathrm{ml}$ aprotinin, and $10 \mu \mathrm{g} / \mathrm{ml}$ leupeptin ( $\mathrm{pH}$ 7.4). After 10 min incubation cells were homogenised with 30 strokes of a Dounce homogeniser using a tight-fitting pestle. Nuclei were pelleted by centrifugation at $500 \mathrm{~g}$ for $5 \mathrm{~min}$, and the low-speed supernatant was centrifuged at $100,000 \mathrm{~g}$ for $30 \mathrm{~min}$. The high-speed supernatant constituted the internal 
$\mathbf{a}$
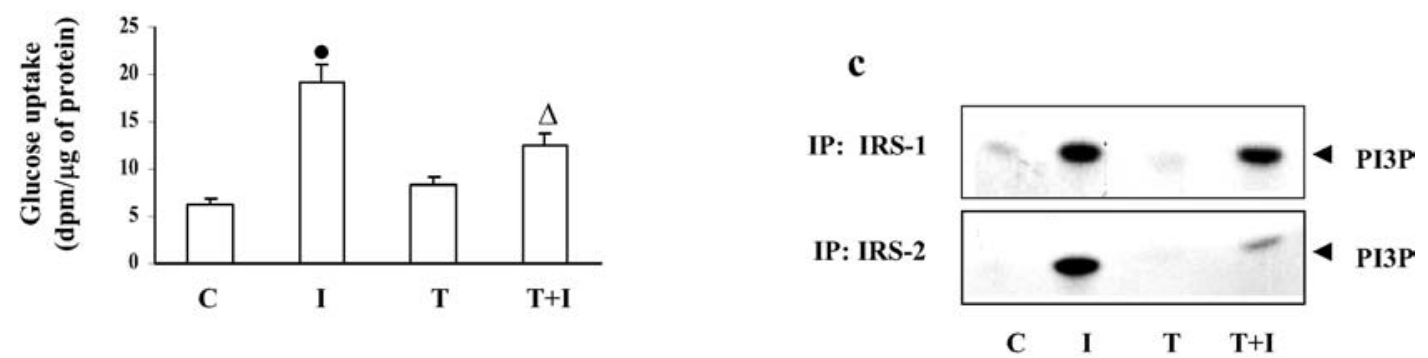

b
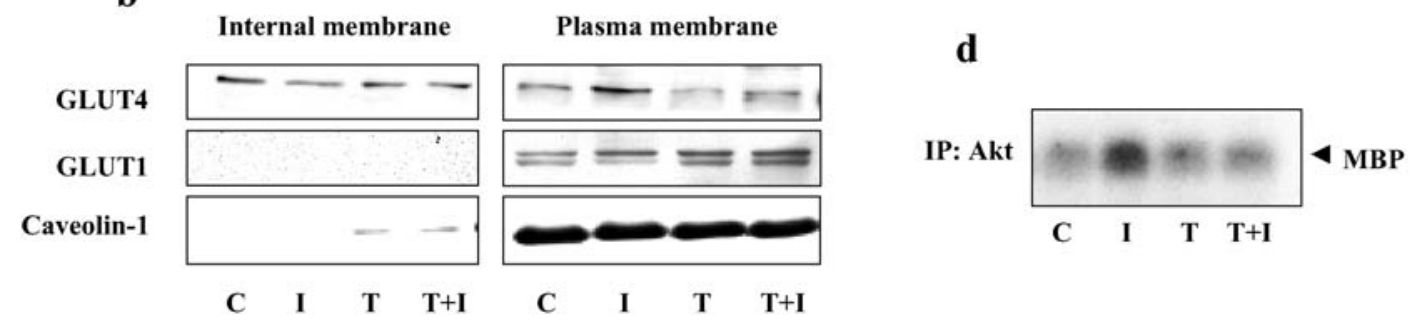

Fig. 1. TNF- $\alpha$ causes insulin resistance in cultured fetal brown adipocytes. Cells were serum-deprived for $20 \mathrm{~h}$ and further cultured for $24 \mathrm{~h}$ in the absence $(\mathrm{C})$ or presence $(\mathrm{T})$ of $1 \mathrm{nmol} / \mathrm{l}$ TNF- $\alpha$ and stimulated or not for 30 minutes with $10 \mathrm{nmol} / \mathrm{l}$ insulin (I). For panels (c) and (d), the time of insulin stimulation was 5 minutes. Glucose uptake (a) was measured during the last 10 minutes by incorporation of 2-deoxy-D[1-3 $\mathrm{H}]$-glucose into the cells. Results are means \pm SEM $(n=10)$. Statistical significance was tested and differences between values in the presence of I vs control (C) are represented by filled circles $(p<0.001)$, differences between values in the presence of $\mathrm{T}+\mathrm{I}$ vs I are represented by open triangles $(p<0.01)$. b. Cells were harvested and submitted to subcellular fractionation. Western blotting was done on $10 \mu \mathrm{g}$ of internal and plasma membrane proteins from each condition, using anti-GLUT4, anti-GLUT1 and anti-Caveolin-1 antibodies, and developed with ECL. Cell lysates were immunoprecipitated with anti-IRS-1 or anti-IRS-2 antibodies (c) and assayed for PI 3-kinase activity or with antiAkt (d) and assayed for MBP phosphorylation. Representative blots from four independent experiments are shown

membrane fraction. The pellet was washed three times and extracted in ice-cold homogenisation buffer containing $1 \%$ Triton X-100 for $60 \mathrm{~min}$. The Triton-soluble component (plasma membrane fraction) was separated from the Triton-insoluble material (cytoskeletal fraction) by centrifugation at $100,000 \mathrm{~g}$ for $15 \mathrm{~min}$. Internal and plasma membrane fractions were kept at $-70{ }^{\circ} \mathrm{C}$ before protein quantification and western blotting with GLUT4, GLUT1 and caveolin-1 antibodies [23].

Immunoprecipitations. Cells were extracted with lysis buffer I containing: $10 \mathrm{mmol} / \mathrm{l}$ Tris, $50 \mathrm{mmol} / \mathrm{l} \mathrm{NaCl}, 1 \%$ Triton $\mathrm{X}-100$, $5 \mathrm{mmol} / \mathrm{l}$ EDTA, $20 \mathrm{mmol} / \mathrm{l}$ sodium pyrophosphate, $50 \mathrm{mmol} / \mathrm{l}$ $\mathrm{NaF}, 100 \mu \mathrm{mol} / \mathrm{l} \mathrm{Na} 3 \mathrm{VO} 4,1 \mathrm{mmol} / \mathrm{l} \mathrm{PMSF}$ (pH 7.5), and then immunoprecipitated with different antibodies. PI 3-kinase activity was measured in anti-IRS-2 or anti-IRS-1 immunoprecipitates by in vitro phosphorylation of PI as previously described [23]. To determine Akt and p38MAPK activities, lysates were immunoprecipitated with anti-Akt or antip38MAPK and the immune complexes were used for in vitro phosphorylation of MBP as described [19, 30].

Western blotting. Cells were lysed in lysis buffer I and cellular proteins $(30 \mu \mathrm{g})$ were submitted to SDS-PAGE, transferred to Immobilon membranes and blocked using 5\% non-fat dried milk in $10 \mathrm{mmol} / \mathrm{l}$ Tris- $\mathrm{HCl}$ and $150 \mathrm{mmol} / \mathrm{l} \mathrm{NaCl} \mathrm{pH} \mathrm{7.5.}$ They were then incubated overnight with several antibodies as indicated in each case in $0.05 \%$ Tween-20, $1 \%$ non-fat dried milk in $10 \mathrm{mmol} / \mathrm{l}$ Tris- $\mathrm{HCl}$ and $150 \mathrm{mmol} / \mathrm{l} \mathrm{NaCl} \mathrm{pH} \mathrm{7.5.} \mathrm{Im-}$ munoreactive bands were visualised using the enhanced chemiluminiscence (ECL-Plus) western blotting protocol (Amersham).

JNK assay. Cell lysates were obtained as described for immunoprecipitation. A pull-down of JNKs was performed with glutathione-S-transferase-c-Jun 79 protein, as described [31].

Data analysis. Results are means \pm SEM $(n=4-10)$ for duplicate dishes from four to ten independent experiments. Statistical significance was tested with ANOVA, followed by the protected least significant different test. A $p$ value of less than 0.05 was considered significant. In experiments using X-ray films (Hyperfilm), different exposure times were used to ensure that bands were not saturated.

\section{Results}

Characterisation of TNF- $\alpha$ signalling pathways that contribute to insulin resistance in brown adipocytes. TNF- $\alpha$ inhibited insulin-stimulated glucose uptake in several systems including primary fetal brown adipocytes. Cells pretreated with TNF- $\alpha$ for $24 \mathrm{~h}$ had a glucose uptake $30 \%$ higher than untreated cells. Insulin stimulation for $30 \mathrm{~min}$ increased basal glucose uptake 3 -fold, but only produced a 1.5 -fold increase in the glucose uptake of cells treated with TNF- $\alpha, 50 \%$ lower than that observed in the absence of TNF- $\alpha$ (Fig. 1a).

Insulin stimulation of glucose transport is mediated by the translocation of GLUT4 to the plasma membrane. To correlate the data on glucose uptake with 
a

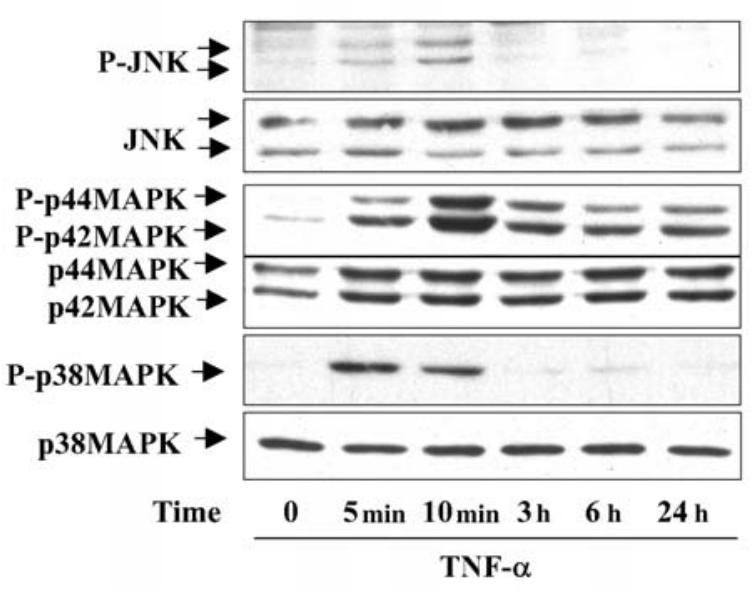

c

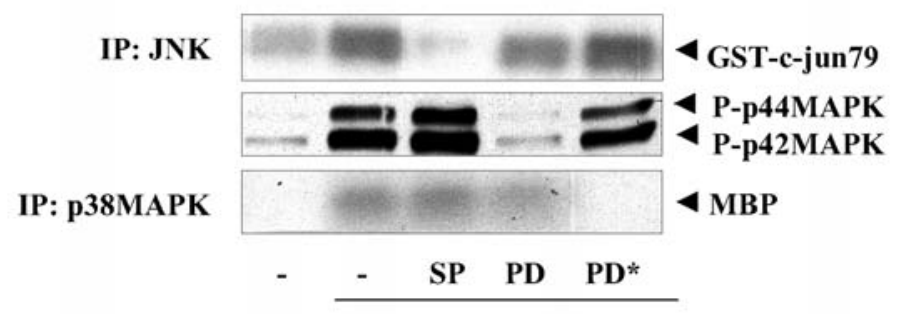

b
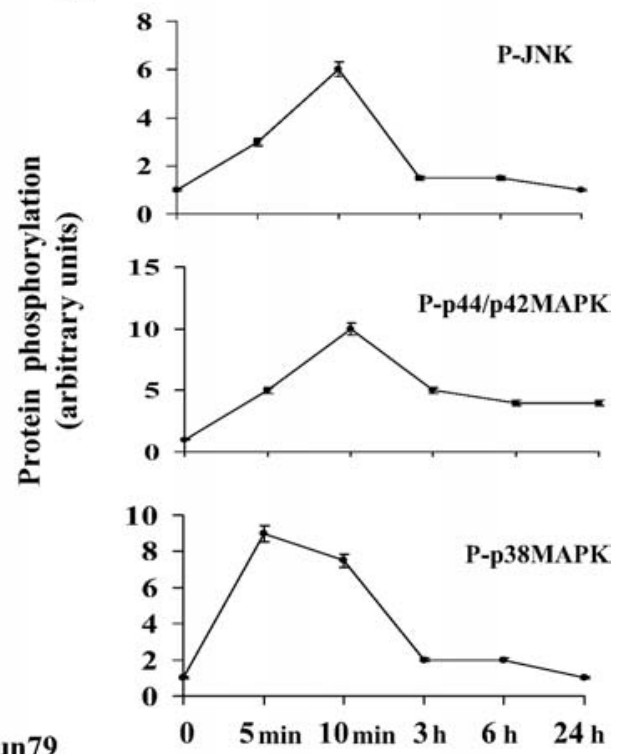

TNF- $\alpha$

Fig. 2. TNF- $\alpha$ activates several kinases in fetal brown adipocyte primary cultures. a. Cells were serum-deprived for $20 \mathrm{~h}$ and further cultured for up to $24 \mathrm{~h}$ with or without $1 \mathrm{nmol} / \mathrm{l}$ TNF- $\alpha$. Cells were then collected and protein extracts were analysed by western blotting with the corresponding antibodies against phosphorylated and total JNK, p42/p44MAPK and p38MAPK (representative blots are shown). Graphs (b) show densitometric analysis of phosphorylated proteins after standardisation using the total amount of protein. Values (means \pm SEM, $n=4$ ) are expressed in arbitrary units, in which a value of 1 was assigned for kinase activity prior to stimulation with TNF- $\alpha$. c. Cells were pretreated or not for 30 minutes with the inhibitors PD169316 (PD*, $800 \mathrm{nmol} / \mathrm{l}$ ), PD98059 (PD, $20 \mu \mathrm{mol} / \mathrm{l}$ ) and SP600125 (SP, $3 \mu \mathrm{mol} / \mathrm{l})$ and further incubated for 10 minutes with $1 \mathrm{nmol} / \mathrm{l}$ TNF- $\alpha$. Then protein extracts were immunoprecipitated with anti-p38MAPK or pull-down with GST-c-Jun 79 for in vitro activity assays, or were analysed by western blotting for phosphorylated p42/p44MAPK. Representative experiments are shown

GLUT4 translocation, cells were pretreated or not with TNF- $\alpha$ for $24 \mathrm{~h}$ and stimulated with insulin for a further $30 \mathrm{~min}$. Subcellular fractionation was then performed to obtain plasma membrane and internal membrane, and GLUT4 protein was detected by immunoblotting. Insulin increased GLUT4 translocation to the plasma membrane 3 -fold with a concomitant decrease in the amount of GLUT4 in the internal membrane. This redistribution of GLUT4 was precluded after TNF- $\alpha$ treatment (Fig. 1b). However, TNF- $\alpha$ in- creased GLUT1 protein content at the plasma membrane, probably contributing to the increase observed in basal glucose uptake. Caveolin-1, an integral membrane protein from caveolae, was used as a marker protein of the plasma membrane and under the different treatments used the amount of caveolin-1 remained essentially unaltered.

The PI 3-kinase/Akt pathway has been broadly implicated in insulin stimulation of GLUT4 translocation. In brown adipocytes, insulin activated PI 3-kinase was associated either with IRS-1 or IRS-2 to a similar extent. TNF- $\alpha$ hardly modified insulin-induced PI 3-kinase activity associated with IRS-1, but it did inhibit PI 3-kinase activity associated with IRS2 (Fig. 1c). Immunoprecipitation with the anti-Akt antibody and determination of the enzymatic activity revealed that TNF- $\alpha$ prevented insulin-stimulated Akt activation (Fig. 1d).

The molecular mechanism by which TNF- $\alpha$ induces insulin resistance is far from clear. This prompted us to investigate the signalling pathways elicited by TNF- $\alpha$ in brown adipocytes. Cells were deprived of serum for $20 \mathrm{~h}$ and further cultured for up to $24 \mathrm{~h}$ in the presence of $1 \mathrm{nmol} / \mathrm{l} \mathrm{TNF}-\alpha$. At the end of the culture time cells were collected and protein extracts were analysed for activation of stress kinases (Fig. 2). TNF- $\alpha$ produced a transient phosphorylation of p38MAPK at 5 min and of JNK at $10 \mathrm{~min}$. These activations were not detectable after $3 \mathrm{~h}$ of treatment. However, TNF- $\alpha$ in- 


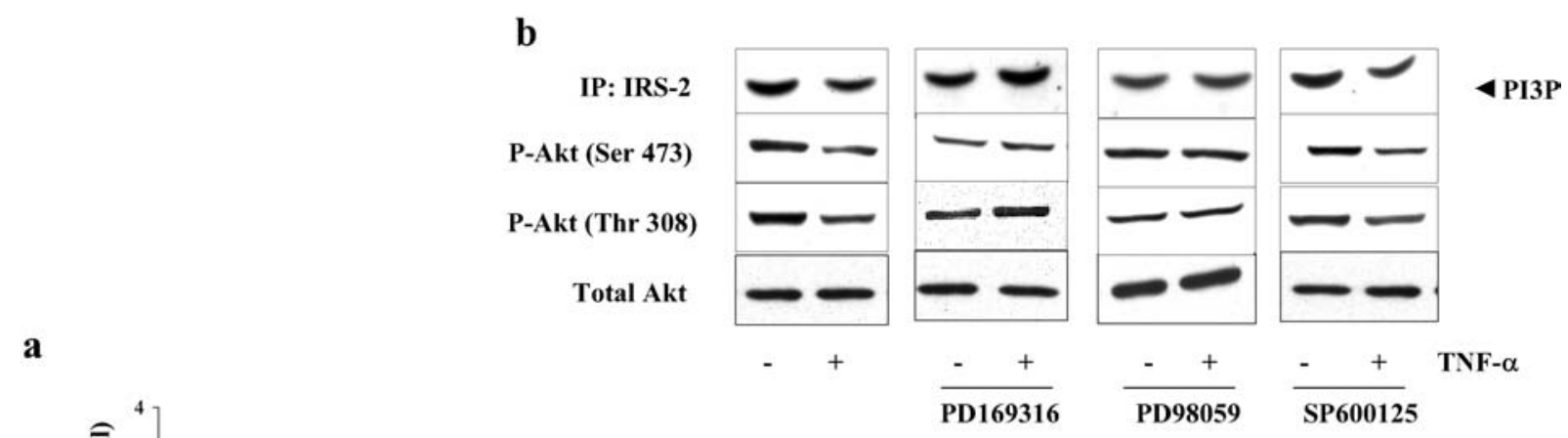

Fig. 3. Effect of inhibitors on $\mathrm{TNF}-\alpha$-induced insulin resistance in brown adipocytes. a. Cells were cultured for $24 \mathrm{~h}$ in the absence or presence of $1 \mathrm{nmol} / \mathrm{l} \mathrm{TNF}-\alpha$ and without or with the inhibitors PD169316 (PD*, $800 \mathrm{nmol} / \mathrm{l}$ ), PD98059 (PD, $20 \mu \mathrm{mol} / \mathrm{l}$ ) and SP600125 (SP, $3 \mu \mathrm{mol} / \mathrm{l}$ ). They were then stimulated or not for 30 minutes with $10 \mathrm{nmol} / \mathrm{l}$ insulin. Glucose uptake was measured during the last 10 minutes by incorporating 2-deoxy-D $\left[1-{ }^{3} \mathrm{H}\right]$-glucose into the cells. Results are expressed as fold increase over basal glucose uptake without insulin and are means \pm SEM $(n=10)$. Cells (b) were cultured as above, but with only $5 \mathrm{~min}$ insulin stimulation. Cell lysates were immunoprecipitated with anti-IRS-2 antibody and assayed for PI 3-kinase activity. Cell lysates were also analysed by western blotting, using the corresponding antibodies against phospho-Akt (Ser473), phospho-Akt (Thr308) and total Akt. Representative experiments are shown. c. The resulting densitometric analysis from four independent experiments. Filled bars: without TNF- $\alpha$; open bars: with TNF- $\alpha$. Results (means \pm SEM) are expressed in arbitrary units, in which a value of 100 was assigned for kinase activity in the presence of insulin. Statistical significance was tested and differences between values in the presence of TNF- $\alpha$ vs absence of TNF- $\alpha$ are represented by the open triangle $(p<0.01)$

duced the maximal phosphorylation of p42/p44MAPK at $10 \mathrm{~min}$, this kinase remaining activated throughout the treatment (24 h) (Fig. 2a, b).

Since TNF- $\alpha$ activated several kinases in brown adipocytes, we decided to impair these pathways with chemical inhibitors and determine if TNF- $\alpha$ produced insulin resistance under those circumstances. We used SP600125 (3 $\mu \mathrm{mol} / \mathrm{l})$ to inhibit JNK, PD98059 c

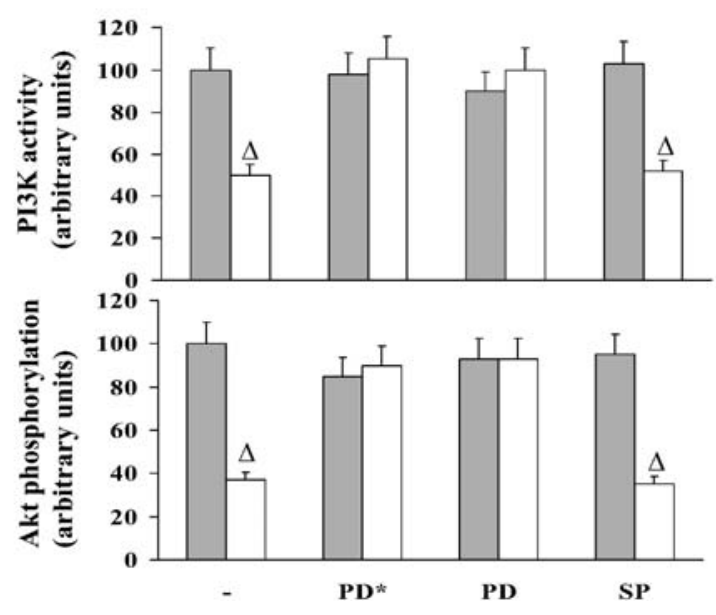

(20 $\mu \mathrm{mol} / \mathrm{l})$ to inhibit extracellular signal-regulated kinase (ERK) and PD169316 (800 nmol/l) as p38MAPK inhibitor, having previously tested the specificity and optimal inhibitory doses of these compounds in brown adipocytes (Fig. 2c). Cells were deprived of serum for $20 \mathrm{~h}$ and further cultured for $24 \mathrm{~h}$ in the absence or presence of $1 \mathrm{nmol} / \mathrm{l} \mathrm{TNF}-\alpha$ with or without inhibitors, prior to stimulation for $30 \mathrm{~min}$ with $10 \mathrm{nmol} / \mathrm{l}$ insulin. Glucose uptake was measured during the last $10 \mathrm{~min}$ of culture and results were expressed as fold increase over basal glucose uptake in the absence of insulin (Fig. 3a). As described above, insulin increased basal glucose uptake (3-fold) and TNF- $\alpha$ treatment inhibited insulin stimulation by $50 \%$. When cells were cultured for $24 \mathrm{~h}$ in the presence of PD169316 or PD98059, insulin increased glucose uptake by 2.8 -fold regardless of whether TNF- $\alpha$ was present or not. However, SP600125 at the optimal dose for JNK inhibition did not prevent insulin resistance by TNF- $\alpha$ (Fig. 3a). These data seem to indicate that although TNF- $\alpha$ activates several kinases in brown adipocytes, it is mostly p42/p44 and p38MAPK that contribute to the inhibitory effect of TNF- $\alpha$ on insulin-stimulated glucose uptake.

As TNF- $\alpha$ interferes with the insulin signalling cascade at the level of IRS-2, with the subsequent inhibition of PI 3-kinase and Akt, we next checked whether the inhibitors named above could block interference at this level. Cells were deprived of serum for $20 \mathrm{~h}$ and further cultured for $24 \mathrm{~h}$ in the absence or 

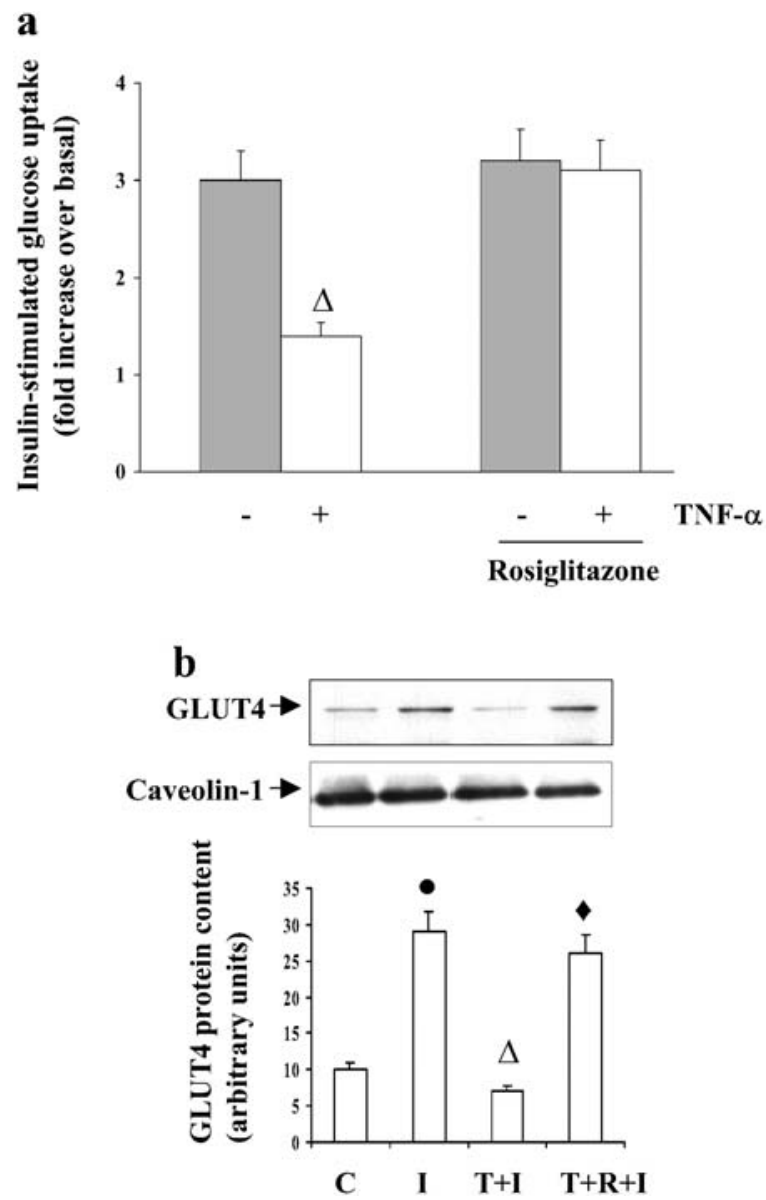

Fig. 4. Rosiglitazone restored insulin-stimulated glucose uptake, GLUT4 translocation and the IRS-2/PI 3-kinase/Akt cascade in the presence of TNF- $\alpha$. Cells were cultured for $24 \mathrm{~h}$ in the absence or presence of $1 \mathrm{nmol} / \mathrm{l} \mathrm{TNF}-\alpha$ (T) and/or $10 \mu \mathrm{mol} / \mathrm{l}$ rosiglitazone $(\mathrm{R})$ and stimulated or not for $30 \mathrm{~min}$ utes with $10 \mathrm{nmol} / 1$ insulin (I). a. Results for glucose uptake are expressed as in Figure 3a. Statistical significance was also tested as in Figure 3. b. Cells were harvested and subjected to subcellular fractionation. Western blotting was done on $10 \mu \mathrm{g}$ of plasma membrane proteins from each condition, using antiGLUT4 and anti-Caveolin-1 antibodies (representative blot is shown). Corresponding autoradiograms for GLUT4 were quantitated by scanning densitometry. Results (means \pm SEM, $n=4$ ) are expressed as arbitrary units, in which a value of 10 was assigned for control. Representative western blot analysis (c) is of GLUT4, GLUT1 and FAS from brown adipocytes, treated $(\mathrm{R})$ or not $(\mathrm{C})$ for $24 \mathrm{~h}$ with rosiglitazone. d. Cells were cultured as above, but insulin stimulation was for 5 min only. Cell lysates were immunoprecipitated with anti-IRS-2 antibody and assayed for PI 3-kinase activity. Cell lysates were also analysed by western blotting with the corresponding antibodies against phospho-Akt (Ser473), phospho-Akt (Thr308) and total Akt (representative blots are shown). Values in graphs from densitometric analysis (means \pm SEM, $n=4$ ) are expressed as arbitrary units, in which a value of 10 was assigned for control. Statistical significance was tested $(\mathbf{b}, \mathbf{d})$ and differences between values in the presence of I vs control (C) are represented by a closed circle $(p<0.001)$, between values in the presence of $\mathrm{T}+\mathrm{I}$ vs I by an open triangle $(p<0.01)$, and between values in the presence of $\mathrm{T}+\mathrm{R}+\mathrm{I}$ vs $\mathrm{T}+\mathrm{I}$ by a closed diamond $(p<0.01)$

\section{c}

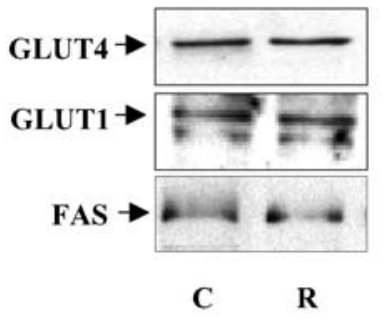

d
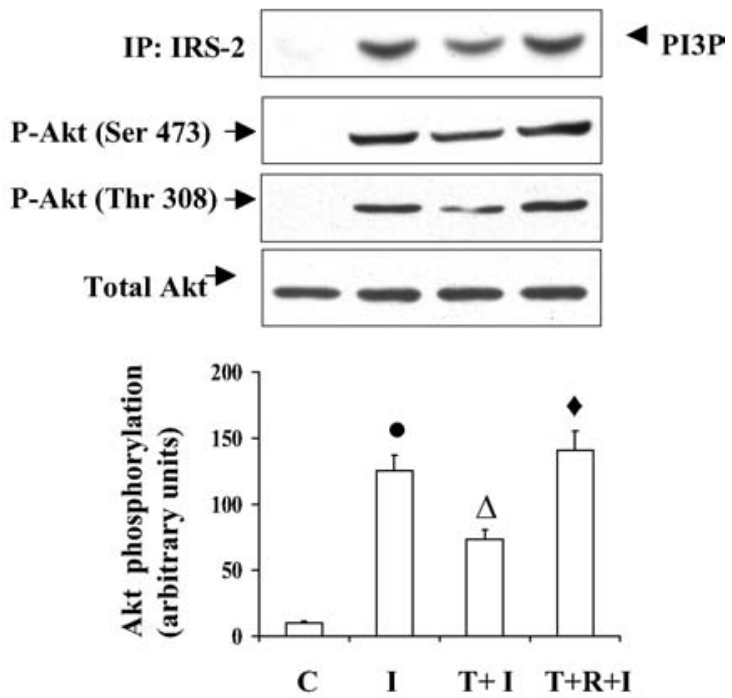

presence of $1 \mathrm{nmol} / \mathrm{l}$ TNF- $\alpha$ with or without inhibitors, prior to stimulation for 5 min with $10 \mathrm{nmol} / \mathrm{l}$ insulin. PI 3-kinase activity was determined in the immune complexes after immunoprecipitation with the anti-IRS-2 antibody. In addition, cell lysates were analysed by western blotting with anti-phospho Akt antibodies for the regulatory residues Ser473 and Thr308, as well as with total Akt antibody (Fig. 3b). As expected, TNF- $\alpha$ inhibited insulin-activated PI 3kinase that is associated with IRS-2. Moreover, upon insulin stimulation, Akt was highly Ser- and Thrphosphorylated, both effects being impaired by pretreatment with TNF- $\alpha$, which was consistent with our data on Akt activity (Fig. 1d). Under chronic treatment with SP600125 together with TNF- $\alpha$, PI 3-kinase and Akt phosphorylation by insulin also decreased compared with the activation detected in the absence of TNF- $\alpha$. However, when cells were cultured in the presence of PD169316 or PD98059, TNF$\alpha$ did not produce insulin resistance at the level of PI 3-kinase associated to IRS-2 or phosphorylated Akt (Fig. 3b, c). This is consistent with the results for insulin-stimulated glucose uptake (Fig. 3a).

Rosiglitazone ameliorates insulin resistance by impairing TNF- $\alpha$ activation of $p 38$ and p42/p44 MAPKs. Insulin resistance caused by $\mathrm{TNF}-\alpha$ in brown adipocytes can be reduced by treatment with 
a

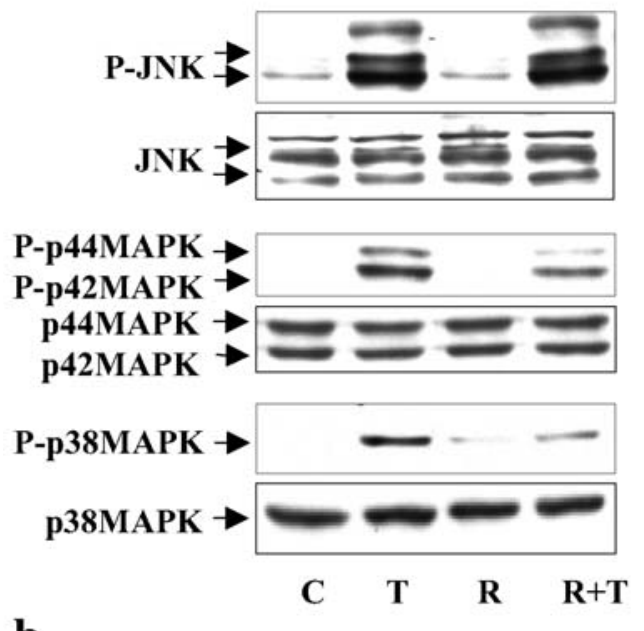

b

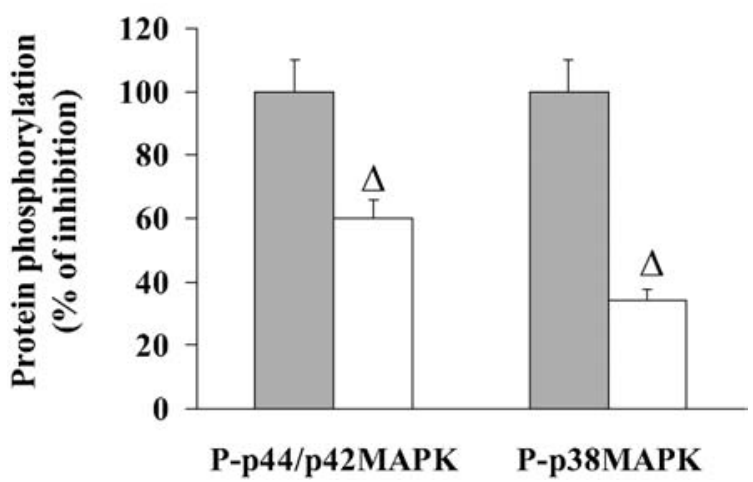

Fig. 5. Rosiglitazone impairs the stimulation of $\mathrm{p} 38$ and p42/p44 MAPKs produced by TNF- $\alpha$. Cells (a) were cultured for $24 \mathrm{~h}$ in the absence or presence $10 \mu \mathrm{mol} / \mathrm{l}$ rosiglitazone $(\mathrm{R})$ and stimulated or not for 10 minutes with $1 \mathrm{nmol} / 1 \mathrm{TNF}-\alpha(\mathrm{T})$. Cell lysates were submitted to western blotting with the corresponding antibodies against phosphorylated and total JNK, p42/p44MAPK and p38MAPK (representative blots are shown). C, control. b. Values in graphs from densitometric analysis (means \pm SEM, $n=4$ ) are expressed as arbitrary units in which a value of 100 was assigned for kinase activity in the presence of TNF- $\alpha$. Grey bars: with TNF- $\alpha$; open bars: with rosiglitazone + TNF- $\alpha$. Statistical significance was tested and differences between values in the presence of $\mathrm{R}$ vs its absence are represented by an open triangle $(p<0.05)$

PD169316 or PD98059. However, as these compounds are experimental tools, we tested rosiglitazone, a compound used in clinical studies to treat Type 2 diabetes, and checked the mechanism by which it restores insulin signalling and/or antagonises TNF- $\alpha$ signalling. Cells were deprived of serum for $20 \mathrm{~h}$ and further cultured for $24 \mathrm{~h}$ in the absence or presence of $1 \mathrm{nmol} / \mathrm{l} \mathrm{TNF}-\alpha$ with or without $10 \mu \mathrm{mol} / \mathrm{l}$ rosiglitazone, prior to stimulation for $30 \mathrm{~min}$ with $10 \mathrm{nmol} / \mathrm{l}$ insulin. Under these conditions glucose uptake and GLUT4 translocation to the plasma membrane were determined (Fig. 4a, b). Rosiglitazone completely impaired TNF- $\alpha$-induced insulin resis- tance on glucose uptake (Fig. 4a) and restored GLUT4 translocation by insulin (Fig. 4b), without modifying levels of GLUT4, GLUT1 and FAS proteins (Fig. 4c). In parallel to glucose uptake, rosiglitazone completely restored insulin stimulation of IRS-2-associated PI 3kinase and Akt phosphorylation in the presence of TNF- $\alpha$ (Fig. 4d).

Finally, we investigated whether rosiglitazone treatment antagonised the activation of kinases by TNF- $\alpha$, some of which are involved in insulin resistance as indicated (Fig. 3). Cells were treated with rosiglitazone for $24 \mathrm{~h}$ prior to TNF- $\alpha$ treatment for $10 \mathrm{~min}$, and the activation of stress kinases was determined (Fig. 5a). Rosiglitazone impaired TNF- $\alpha$ activation of p38MAPK and ERK, without affecting JNK activation (Fig. 5b).

\section{Discussion}

TNF- $\alpha$ produced opposing physiological effects to insulin in the murine 3T3-L1 cell line, in human primary adipocytes and, as we previously showed, in rat primary brown adipocytes, inhibiting insulin-stimulated glucose uptake $[4,5,22,23,32]$. There are differences in the level at which TNF- $\alpha$ antagonisation of insulin signalling occurs: impaired insulin signalling at the IRS-1 level has been demonstrated for white adipocytes [7, 8], but chronic exposure to TNF- $\alpha$ caused insulin resistance in brown adipocytes by decreasing IRS-2 Tyr phosphorylation and IRS-2-associated PI 3-kinase activity, with IRS-1 signalling being unaffected [22]. Downstream PI 3-kinase Akt activation by insulin but not PKC $\zeta$ was also impaired under chronic TNF- $\alpha$ treatment in brown fat [23]. The molecular mechanism underlying TNF- $\alpha$-mediated insulin resistance could involve activation of different Ser/Thr kinases by TNF- $\alpha$, and in this regard MAPKs (JNK, ERK and p38), as well as IKK, were activated by TNF- $\alpha$ in fat cells $[13,33]$. In this work, we show that TNF- $\alpha$ produced a transient phosphorylation of p38MAPK at $5 \mathrm{~min}$ and of JNK at $10 \mathrm{~min}$, as well as a sustained activation of $\mathrm{p} 42 / \mathrm{p} 44 \mathrm{MAPK}$ throughout the 24-h treatment in brown adipocytes, the activation of these pathways seeming to be independent from each other.

To better understand the contribution of these kinases to insulin resistance, we used chemical inhibitors of these pathways in order to restore insulin signalling to normal levels despite the presence of TNF- $\alpha$. The impairment of insulin stimulation of glucose uptake was abrogated by pretreatment with the inhibitor of p42/p44MAPK, PD98059, as well as with the inhibitor of p38MAPK, PD169316, with a complete restoration of IRS-2-associated PI 3-kinase activity and Akt phosphorylation by insulin. However, SP600125, an inhibitor of JNK, failed to prevent insulin resistance through TNF- $\alpha$ 's effect on glucose uptake and insulin signalling. 
Both ERK and JNK have been said to mediate Ser/Thr phosphorylation of IRS-1 by TNF- $\alpha$, weakening its Tyr phosphorylation by insulin and impairing the normal response to insulin on glucose uptake and lipolysis in white fat cells $[9,10,12,33]$. In this regard, recent works have indicated that ERK, to a greater extent than p38MAPK and JNK, could inhibit insulin signalling at the level of IRS-1 and IRS-2 in 3T3-L1 adipocytes [13], while JNK mediated feedback inhibition of insulin signalling [34]. Moreover, increased phosphorylation of p38MAPK in human adipocytes and muscle from Type 2 diabetic subjects has recently been described $[35,36]$, suggesting a key role for this kinase in the development of insulin resistance and Type 2 diabetes. Our data indicate that ERK and p38MAPK could be major factors in TNF- $\alpha$-induced insulin resistance in brown adipocytes, acting at the level of IRS-2, in agreement with our previous findings for a more prevalent implication of this docking protein in brown adipocytes as well as in other insulin-responsive cells [22, 23, 37]. Constitutive Ser/Thr phosphorylation is found in IRSs since more than a hundred of these residues are present in these proteins, as we recently detected in skeletal muscle cells [38]. However, additional Ser phosphorylation, as that induced when TNF- $\alpha$ activates ERK and p38MAPK, could inhibit IRS function. Based on sequence homology from data bases (online tool at http://scansite.mit.edu, last accessed 16/4/2004), Ser904 could be a potential ERK phosphorylation site in IRS-2, Ser652 could be a potential phosphorylation site for p38MAPK, and Ser367 is a phosphorylation site common to both kinases. Thus, it is possible that phosphorylation of these three residues in the IRS-2 protein will be necessary to produce insulin resistance in brown adipocytes, although we cannot rule out the involvement of other residues.

The ability of thiazolidinediones to ameliorate insulin resistance induced by TNF- $\alpha$ is well documented [39, $40,41]$. However, the mechanisms by which these compounds impair the activity of TNF- $\alpha$ are not understood. In this work we found that chronic exposure to rosiglitazone, as in human clinical use, completely restored insulin-induced glucose uptake and GLUT4 translocation in the presence of TNF- $\alpha$, without modifying the expression of GLUT4 or GLUT1. Glucose uptake has been found to be increased by thiazolidinediones in isolated adipocytes and in 3T3-L1 adipocytes as a result of increased GLUT4 or GLUT1 expression [42, 43]. However, we demonstrate that this effect is a consequence of GLUT4 translocation in brown adipocytes. Our data also demonstrate a powerful effect of rosiglitazone in restoring insulin sensitivity upon activation of PI 3-kinase associated with IRS-2, and upon Akt phosphorylation, in TNF- $\alpha$-treated brown adipocytes. This effect does not seem to be related to the differentiation-inducing properties of rosiglitazone, because levels of the adipogenic protein FAS remain unmodified.
Pioglitazone has also been reported to reduce TNF$\alpha$-induced insulin resistance in 3T3-L1 cells by a mechanism independent of the adipogenic activity of PPAR $\gamma$ [44]. In that model restoration of insulin response was mostly produced at the level of IRS-1/PI 3 -kinase. Since our data indicated that TNF- $\alpha$-induced insulin resistance could be mediated, at least in part, by activation of p38MAPK and ERK, we investigated whether rosiglitazone antagonises TNF- $\alpha$ signalling. In this regard, pretreatment with rosiglitazone impaired $\mathrm{p} 38$ and $\mathrm{p} 42 / \mathrm{p} 44 \mathrm{MAPK}$ activation by TNF- $\alpha$, while JNK activation was not modified. These results are in agreement with those reported by Souza [45], who found that rosiglitazone blocked TNF- $\alpha$-induced ERK but not JNK activation in 3T3-L1 adipocytes, resulting in reduced lipolysis. Our data indicate that rosiglitazone ameliorates TNF- $\alpha$-induced insulin resistance by antagonising TNF- $\alpha$ activation of $\mathrm{p} 38$ and p42/p44 MAPKs, previously identified as the Ser/Thr kinases involved in insulin resistance in brown adipocytes. Very recent data supporting our findings report hyperphosphorylation of p38MAPK and increased IRS-1 Ser307 phosphorylation in adipose tissues of Zucker obese rats, both effects being reduced by treatment with rosiglitazone [46].

In conclusion, rosiglitazone treatment impaired TNF- $\alpha$ activation of p38MAPK and ERK, ameliorating TNF- $\alpha$ antagonism of the insulin signalling cascade IRS-2/PI 3-kinase and Akt, and completely restorating glucose uptake and GLUT4 translocation in cultured brown adipocytes.

Acknowledgements. T. Teruel is the recipient of a postdoctoral fellowship from the Comunidad Autonoma de Madrid. R. Hernandez and C. de Alvaro are recipients of postgraduate fellowships from the Ministerio de Educacion y Cultura. This work was supported by Grant BMC2002-01322 from Ministerio de Ciencia y Tecnologia, Spain. We are also grateful for the support of COST B17 Action on "Insulin resistance, obesity and diabetes mellitus in the elderly" from the European Commission, and of Red de grupos de Diabetes Mellitus G03/212 from Instituto de Salud Carlos III, Ministerio de Sanidad y Consumo, Spain. We acknowledge the help of I. Nieto in bioinformatics. R. Hernandez and T. Teruel contributed equally to the experimental work.

\section{References}

1. Hotamisligil GS, Shargill NS, Spiegelman BM (1993) Adipose expression of tumor necrosis factor-alpha: direct role in obesity-linked insulin resistance. Science 259:87-91

2. Hotamisligil GS (1999) Mechanisms of TNF-alpha-induced insulin resistance. Exp Clin Endocrinol Diabetes 107:119-125

3. Uysal KT, Wiesbrock SM, Marino MW, Hotamisligil GS (1997) Protection from obesity-induced insulin resistance in mice lacking TNF-alpha function. Nature 389:610-614

4. Hotamisligil GS, Murray DL, Choy LN, Spiegelman BM (1994) Tumor necrosis factor alpha inhibits signalling from the insulin receptor. Proc Natl Acad Sci USA 91:4854-4858 
5. Liu LS, Spelleken M, Rohrig K, Hauner H, Eckel J (1998) Tumor necrosis factor-alpha acutely inhibits insulin signalling in human adipocytes: implication of the p80 tumor necrosis factor receptor. Diabetes 47:515-522

6. Wang CN, O’Brien L, Brindley DN (1998) Effects of cellpermeable ceramides and tumor necrosis factor-alpha on insulin signalling and glucose uptake in 3T3-L1 adipocytes. Diabetes 47:24-31

7. Hotamisligil GS, Peraldi P, Budavari A, Ellis R, White MF, Spiegelman BM (1996) IRS-1-mediated inhibition of insulin receptor tyrosine kinase activity in TNF-alpha- and obesity-induced insulin resistance. Science 271:665-668

8. Sykiotis GP, Papavassiliou AG (2001) Serine phosphorylation of insulin receptor substrate-1: a novel target for the reversal of insulin resistance. Mol Endocrinol 15:1864-1869

9. Rui L, Aguirre V, Kim JK et al. (2001) Insulin/IGF-1 and TNF-alpha stimulate phosphorylation of IRS-1 at inhibitory Ser307 via distinct pathways. J Clin Invest 107:181-189

10. Aguirre V, Werner ED, Giraud J, Lee YH, Shoelson SE, White MF (2002) Phosphorylation of Ser307 in insulin receptor substrate-1 blocks interactions with the insulin receptor and inhibits insulin action. J Biol Chem 277:1531-1537

11. Hirosumi J, Tuncman G, Chang L et al. (2002) A central role for JNK in obesity and insulin resistance. Nature 420:333-336

12. Engelman JA, Berg AH, Lewis RY, Lisanti MP, Scherer PE (2000) Tumor necrosis factor alpha-mediated insulin resistance, but not dedifferentiation, is abrogated by MEK1/2 inhibitors in 3T3-L1 adipocytes. Mol Endocrinol 14: 1557-1569

13. Fujishiro M, Gotoh Y, Katagiri H et al. (2003) Three mitogen-activated protein kinases inhibit insulin signalling by different mechanisms in 3T3-L1 adipocytes. Mol Endocrinol 17:487-497

14. Gao Z, Hwang D, Bataille F et al. (2002) Serine phosphorylation of insulin receptor substrate 1 by inhibitor kappa B kinase complex. J Biol Chem 277:48115-48121

15. Yuan M, Konstantopoulos N, Lee J et al. (2001) Reversal of obesity- and diet-induced insulin resistance with salicylates or targeted disruption of Ikkbeta. Science 293: 1673-1677

16. Teruel T, Valverde AM, Benito M, Lorenzo M (1996) Insulin-like growth factor I and insulin induce adipogenic-related gene expression in foetal brown adipocyte primary cultures. Biochem J 319:627-632

17. Teruel T, Valverde AM, Navarro P, Benito M, Lorenzo M (1998) Inhibition of PI 3-kinase and RAS blocks IGF-I and insulin-induced uncoupling protein 1 gene expression in brown adipocytes. J Cell Physiol 176:99-109

18. Navarro P, Valverde AM, Benito M, Lorenzo M (1998) Insulin/IGF-I rescues immortalized brown adipocytes from apoptosis down-regulating Bcl-xS expression, in a PI 3-kinase- and map kinase-dependent manner. Exp Cell Res 243:213-221

19. Hernandez R, Teruel T, Lorenzo M (2001) Akt mediates insulin induction of glucose uptake and up-regulation of GLUT4 gene expression in brown adipocytes. FEBS Lett 494:225-231

20. Valverde AM, Lorenzo M, Navarro P, Mur C, Benito M (2000) Okadaic acid inhibits insulin-induced glucose transport in foetal brown adipocytes in an Akt-independent and protein kinase C zeta-dependent manner. FEBS Lett 472: $153-158$

21. Lorenzo M, Teruel T, Hernandez R, Kayali AG, Webster NJ (2002) PLCgamma participates in insulin stimulation of glucose uptake through activation of PKCzeta in brown adipocytes. Exp Cell Res 278:146-157
22. Valverde AM, Teruel T, Navarro P, Benito M, Lorenzo M (1998) Tumor necrosis factor-alpha causes insulin receptor substrate-2-mediated insulin resistance and inhibits insulininduced adipogenesis in foetal brown adipocytes. Endocrinology 139:1229-1238

23. Teruel T, Hernandez R, Lorenzo M (2001) Ceramide mediates insulin resistance by tumor necrosis factor-alpha in brown adipocytes by maintaining Akt in an inactive dephosphorylated state. Diabetes 50:2563-2571

24. Olefsky JM (2000) Treatment of insulin resistance with peroxisome proliferator-activated receptor gamma agonists. J Clin Invest 106:467-472

25. Olefsky JM, Saltiel AR (2000) PPAR gamma and the treatment of insulin resistance. Trends Endocrinol Metab 11:362-368

26. Solomon SS, Usdan LS, Palazzolo MR (2001) Mechanisms involved in tumor necrosis factor-alpha induction of insulin resistance and its reversal by thiazolidinedione(s). Am J Med Sci 322:75-78

27. Teruel T, Clapham JC, Smith SA (1999) PPARalpha activation by Wy 14643 induces transactivation of the rat UCP-1 promoter without increasing UCP-1 mRNA levels and attenuates PPARgamma-mediated increases in UCP-1 mRNA levels induced by rosiglitazone in foetal rat brown adipocytes. Biochem Biophys Res Commun 264:311-315

28. Hernandez R, Teruel T, Lorenzo M (2003) Rosiglitazone produces insulin sensitisation by increasing expression of the insulin receptor and its tyrosine kinase activity in brown adipocytes. Diabetologia 46:1618-1628

29. Lorenzo M, Valverde AM, Teruel T, Benito M (1993) IGF$\mathrm{I}$ is a mitogen involved in differentiation-related gene expression in foetal rat brown adipocytes. J Cell Biol 123:1567-1575

30. Teruel T, Hernandez R, Benito M, Lorenzo M (2003) Rosiglitazone and retinoic acid induce uncoupling protein1 (UCP-1) in a p38 mitogen-activated protein kinase-dependent manner in foetal primary brown adipocytes. J Biol Chem 278:263-269

31. Valladares A, Alvarez AM, Ventura JJ, Roncero C, Benito M, Porras A (2000) p38 mitogen-activated protein kinase mediates tumor necrosis factor-alpha-induced apoptosis in rat foetal brown adipocytes. Endocrinology 141:4383-4395

32. Lofgren P, van Harmelen V, Reynisdottir S et al. (2000) Secretion of tumor necrosis factor-alpha shows a strong relationship to insulin-stimulated glucose transport in human adipose tissue. Diabetes 49:688-692

33. Ryden M, Dicker A, van Harmelen V et al. (2002) Mapping of early signalling events in tumor necrosis factor-alpha-mediated lipolysis in human fat cells. J Biol Chem 277:1085-1091

34. Lee YH, Giraud J, Davis RJ, White MF (2003) c-Jun Nterminal kinase (JNK) mediates feedback inhibition of the insulin signalling cascade. J Biol Chem 278:2896-2902

35. Carlson CJ, Koterski S, Sciotti RJ, Poccard GB, Rondinone CM (2003) Enhanced basal activation of mitogen-activated protein kinases in adipocytes from Type 2 diabetes: potential role of p38 in the downregulation of GLUT4 expression. Diabetes 52:634-641

36. Koistinen HA, Chibalin AV, Zierath JR (2003) Aberrant p38 mitogen-activated protein kinase signalling in skeletal muscle from Type 2 diabetic patients. Diabetologia 46:1324-1328

37. Vollenweider P, Menard B, Nicod P (2002) Insulin resistance, defective insulin receptor substrate 2-associated phosphatidylinositol-3' kinase activation, and impaired atypical protein kinase C (zeta/lambda) activation in myotubes from obese patients with impaired glucose tolerance. Diabetes 51:1052-1059 
38. Alvaro C de, Teruel T, Hernandez R, Lorenzo M (2004) Tumor necrosis factor $\alpha$ produces insulin resistance in skeletal muscle by activation of inhibitor $\mathrm{kB}$ kinase in a p38 MAPK-dependent manner. J Biol Chem 279:17070-17078

39. Ruan H, Pownall HJ, Lodish HF (2003) Troglitazone antagonizes tumor necrosis factor-alpha-induced reprogramming of adipocyte gene expression by inhibiting the transcriptional regulatory functions of NF-kappaB. J Biol Chem 278:28181-28192

40. Peraldi P, Xu M, Spiegelman BM (1997) Thiazolidinediones block tumor necrosis factor-alpha-induced inhibition of insulin signalling. J Clin Invest 100:1863-1869

41. Shibasaki M, Takahashi K, Itou T, Bujo H, Saito Y (2003) A PPAR agonist improves TNF-alpha-induced insulin resistance of adipose tissue in mice. Biochem Biophys Res Commun 309:419-424

42. Ciaraldi TP, Kong AP, Chu NV et al. (2002) Regulation of glucose transport and insulin signalling by troglitazone or metformin in adipose tissue of Type 2 diabetic subjects. Diabetes 51:30-36
43. Nugent C, Prins JB, Whitehead JP et al. (2001) Potentiation of glucose uptake in 3T3-L1 adipocytes by PPAR gamma agonists is maintained in cells expressing a PPAR gamma dominant-negative mutant: evidence for selectivity in the downstream responses to PPAR gamma activation. Mol Endocrinol 15:1729-1738

44. Iwata M, Haruta T, Usui I et al. (2001) Pioglitazone ameliorates tumor necrosis factor-alpha-induced insulin resistance by a mechanism independent of adipogenic activity of peroxisome proliferator--activated receptor-gamma. Diabetes 50:1083-1092

45. Souza SC, Palmer HJ, Kang YH et al. (2003) TNF-alpha induction of lipolysis is mediated through activation of the extracellular signal related kinase pathway in 3T3-L1 adipocytes. J Cell Biochem 89:1077-1086

46. Jiang G, Dallas-Yang Q, Biswas S, Li Z, Zhang BB (2004) Rosiglitazone, an agonist of peroxisome proliferator-activated receptor gamma (PPARgamma), reduces inhibitory serine phosphorylation of IRS1 in vitro and in vivo. Biochem J 377:339-346 